
A UNITED STATES DEPARTMENT OF GOMMERGE PUBLICATION

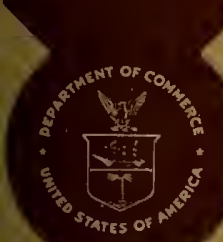

National Bureau of Standards

Library, E-01 Admin. Bidg.

NBS TECHNICAL NOTE 512

\section{The Accuracy of Air Tower Pressure Gages In Suburban Washington, D.C.}


The National Bureau of Standards ${ }^{1}$ was established by an act of Congress March 3, 1901. Today, in addition to serving as the Nation's central measurement laboratory, the Bureau is a principal focal point in the Federal Government for assuring maximum application of the physical and engineering sciences to the advancement of technology in industry and commerce. To this end the Bureau conducts research and provides central national services in four broad program areas. These are: (1) basic measurements and standards, (2) materials measurements and standards, (3) technological measurements and standards, and (4) transfer of technology.

The Bureau comprises the Institute for Basic Standards, the Institute for Materials Research, the Institute for Applied Technology, the Center for Radiation Research, the Center for Computer Sciences and Technology, and the Office for Information Programs.

THE INSTITUTE FOR BASIC STANDARDS provides the central basis within the United States of a complete and consistent system of physical measurement; coordinates that system with measurement systems of other nations; and furnishes essential services leading to accurate and uniform physical measurements throughout the Nation's scientific community, industry, and commerce. The Institute consists of an Office of Measurement Services and the following technical divisions:

Applied Mathematics-Electricity-Metrology-Mechanics-Heat-Atomic and Molecular Physics-Radio Physics *-Radio Engineering "-Time and Frequency 2-Astrophysics "-Cryogenics. ${ }^{2}$

THE INSTITUTE FOR MATERIALS RESEARCH conducts materials research leading to improved methods of measurement standards, and data on the properties of well-characterized materials needed by industry, commerce, educational institutions, and Government; develops, produces, and distributes standard reference materials; relates the physical and chemical properties of materials to their behavior and their interaction with their environments; and provides advisory and research services to other Government agencies. The Institute consists of an Office of Standard Reference Materials and the following divisions:

Analytical Chemistry-Polymers-Metallurgy_Inorganic Materials-Physical Chemistry. THE INSTITUTE FOR APPLIED TECHNOLOGY provides technical services to promote the use of available technology and to facilitate technological innovation in industry and Government; cooperates with public and private organizations in the development of technological standards, and test methodologies; and provides advisory and research services for Federal, state, and local government agencies. The Institute consists of the following technical divisions and offices:

Engineering Standards-Weights and Measures - Invention and Innovation - Vehicle Systems Research-Product Evaluation-Building Research-Instrument Shops-Measurement Engineering-Electronic Technology-Technical Analysis.

THE CENTER FOR RADIATION RESEARCH engages in research, measurement, and application of radiation to the solution of Bureau mission problems and the problems of other agencies and institutions. The Center consists of the following divisions:

Reactor Radiation-Linac Radiation-Nuclear Radiation-Applied Radiation.

THE CENTER FOR COMPUTER SCIENCES AND TECHNOLOGY conducts research and provides technical services designed to aid Government agencies in the selection, acquisition, and effective use of automatic data processing equipment; and serves as the principal focus for the development of Federal standards for automatic data processing equipment, techniques, and computer languages. The Center consists of the following offices and divisions:

Information Processing Standards-Computer Information - Computer Services - Systems Development-Information Processing Technology.

THE OFFICE FOR INFORMATION PROGRAMS promotes optimum dissemination and accessibility of scientific information generated within NBS and other agencies of the Federal government; promotes the development of the National Standard Reference Data System and a system of information analysis centers dealing with the broader aspects of the National Measurement System, and provides appropriate services to ensure that the NBS staff has optimum accessibility to the scientific information of the world. The Office consists of the following organizational units:

Office of Standard Reference Data-Clearinghouse for Federal Scientific and Technical Information "-Office of Technical Information and Publications-Library-Office of Public Information-Office of International Relations.

Teadquarters and Laboratories at Gaithersburg, Maryland, un less otherwise noted; mailing address Washington, D.C. 20234. Located at Boulder, Colorado 80302.

${ }^{3}$ Located at 5285 Port Royal Road, Springfield, Virginia 22151. 
Nat. Bur. Stand. (U.S.), Tech. Note 512, 10 pages (Dec. 1969) CODEN: NBTNA

\title{
The Accuracy of Air Tower Pressure Gages In Suburban Washington, D.C.
}

\author{
B. G. Simson and R. W. Radlinski \\ Office of Vehicle Systems Research \\ Institute for Applied Technology \\ National Bureau of Standards \\ Washington, D.C. 20234
}

\begin{abstract}
NBS Technical Notes are designed to supplement the Bureau's regular publications program. They provide a means for making available scientific data that are of transient or limited interest. Technical Notes may be listed or referred to in the open literature.
\end{abstract}

For sale by the Superintendent of Documents, U.S. Government Printing Office, Washington, D.C. 20402 (Order by SD Catalog No. C 13.46: 512). Price 25 cents 

The Accuracy of Air Tower Pressure Gages in Suburban Washington, D. C.*

B. G. Simson and R. W. Radlinski

A survey of 50 air tower pressure gages in service stations of suburban Washington, D. C., was performed. Results showed that a motorist using these towers has only a 20 percent chance of inflating his tires within \pm 1 psi of the pressure indicated by the tower's gage. It is shown that a calibration of the tower gages would reduce the standard deviation of the obtained pressure to $0.5 \mathrm{psi}$.

Key words: Air towers; tire pressure.

\section{Introduction}

A recent tire usage survey by the Davidson Laboratory of the Stevens Institute of Technology [1] t included an inspection of 72 air tower pressure gages at service stations in the Eastern United States. Results showed that "usually, the air tower delivers a pressure slightly less than the indicated setting." In another study of air towers [2], Consumers Union reports that "about 40 percent of the equipment was off between one and three pounds..."

The work described below deals with air towers at service stations in the suburbs of Washington, D. C. The close proximity of the test stations was chosen to keep environmental conditions, such as temperature and baromentric pressure, as constant as possible. All measurements were completed in about one week.

\section{Test Procedure}

A population of 200 service stations was chosen from the following suburbs of the Washington, D. C., metropolitan area: Chevy Chase, Silver Spring, Rockville, Wheaton, and Gaithersburg. From this population, a random sample of 50 service stations was selected for the survey.

*This work was carried out at the National Bureau of Standards under the sponsorship of the Department of Transportation, National Highway Safety Bureau (FH-11-6090). The opinions, findings, and conclusions expressed in this publication are those of the authors and not necessarily those of the National Highway Safety Bureau.

tFigures in brackets indicate the literature references at the end of this paper. 
The apparatus used to measure the air tower pressure is shown in figure 1. It consists of a 0-60 psi test gage (specified by the manufacture to have an accuracy of $\pm 0.15 \mathrm{psi}$ ) connected to the spare tire of the survey team's vehicle. The air tower gage was set to the desired test pressure and the spare tire (previously deflated to low pressure) was "pumped up" until the tower bell stopped ringing. Then the test gage pressure was recorded. The test pressures* were 20, 24, 28, 32, and 36 psi and the sequence of pressure settings was randomized for each tower. The test gage was checked at the onset and conclusion of each test day against a master gage (specified by its manufacturer to have an accuracy of $\pm 0.10 \mathrm{psi}$ ).

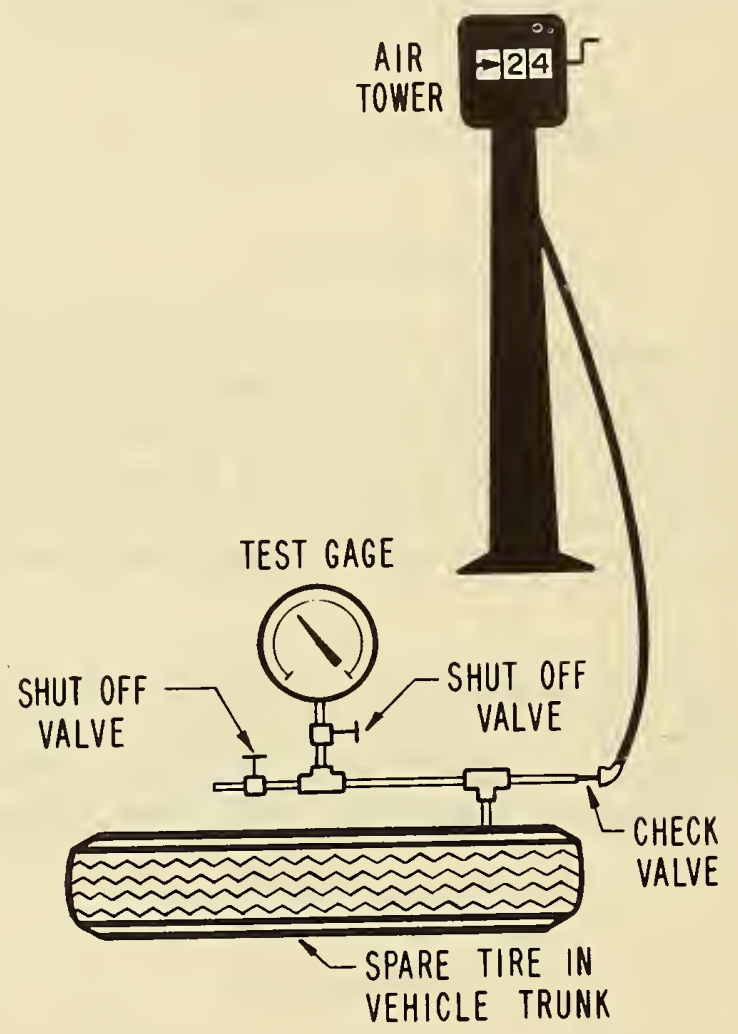

Figure 1. Apparatus for measuring air tower accuracy.

\section{Data}

The data collected from 50 service stations are shown in table 1. Reported are the test gage readings corresponding to air tower gage settings of $20,24,28,32$, and 36 psi, respectively.

*A11 pressures are "gage" pressure, not absolute pressure. 
Table 1. Test gage readings (psi) for various air tower settings

$\begin{array}{r}\text { Samp } \\ 1 \\ 2 \\ 4 \\ 5 \\ 6 \\ 8 \\ \hline\end{array}$

10

11

12

13

14

15

16

17

18

19

20

21

22

23

24

25

26

27

28

29

30

31

32

33

34

35

36

37

38

39

40

41

42

43

44

45

46

47

48

49

50 $\frac{20 \text { psi }}{17.4}$

14.0

18.4

21.5

19.6

19.0

18.8

19.8

18.2

18.6

21.2

19.3

18.8

14.6

16.0

19.7

18.7

21.8

18.0

22.2

21.1

19.7

22.0

16.8

21.2

21.6

20.2

12.6

22.0

20.2

17.0

18.2

18.0

15.0

16.9

19.8

18.5

20.0

13.6

18.0

19.3

20.2

27.5

33.6

32.4

24.5

18.8

22.4

23.2

23.3
Tower Setting

$\frac{24 \text { ps i }}{21.5} \quad \frac{28 \text { ps i }}{25.5}$

18.2

22.3

26.0

22.4

24.6

23.7

23.8

21.0

21.8

23.8

23.2

22.6

19.3

20.0

24.3

22.0

25.9

22.4

26.5

24.5

23.4

25.5

21.3

25.9

25.6

24.5

14.6

25.8

24.2

21.5

21.8

21.4

18.8

21.0

23.7

22.2

24.6

17.4

22.0

23.3

23.7

31.0

37.6

37.6

28.6

23.7

26.8

27.0

28.2
22.0

26.0

30.4

26.2

27.8

27.3

27.9

24.7

26.1

27.8

27.8

26.0

23.6

24.2

29.6

26.0

30.4

25.6

29.7

28.5

28.6

29.4

26.3

28.1

28.8

28.4

19.4

29.4

28.5

25.0

26.5

25.2

21.6

25.1

28.2

26.2

29.3

21.3

25.5

27.3

30.2

35.0

43.7

42.5

32.6

26.8

31.0

30.2

32.2 $\frac{32 \text { psi }}{29.5}$

26.7

30.0

34.2

31.8

31.7

31.5

31.8

29.4

30.3

31.0

31.7

30.2

27.0

27.5

32.4

30.0

34.4

30.0

33.2

32.4

32.6

32.7

29.1

32.7

33.6

32.2

23.0

33.4

32.6

28.0

29.4

29.6

25.4

28.8

32.0

29.7

32.8

25.1

29.2

31.5

31.3

38.5

48.0

46.4

36.4

31.0

34.8

35.2

35.3

36 ps i

33.7

29.6

34.2

38.4

35.2

36.4

35.6

35.2

33.0

33.3

35.7

35.4

34.4

30.7

31.8

36.2

34.3

37.7

33.6

37.4

37.7

37.0

32.9

36.2

36.8

35.9

26.6

37.5

36.8

32.0

33.2

34.5

29.2

33.0

35.4

34.8

35.2

28.7

33.4

35.3

36.0

42.7

52.3 


\section{Statistical Analysis}

An analysis was first made to separate systematic and random type errors in the observed differences between the various towers. It is useful for this purpose to represent the data by an appropriate mathematical model.

The procedure is illustrated in figure 2 . The abscissa represents the average values for all air towers at each of the five settings. The value denoted $C$ is the average of these five averages. The ordinate represents the values obtained by air tower 17. The five points thus obtained fall close to a straight line, which is also shown on the graph. The height of this line at the point $C$ is denoted by $A$ and its slope by $B$.

If $x_{j}$ is the abscissa for the $j$ th point and $y_{j}$ the corresponding ordinate, $j$ the situation is represented by the equation

$$
y_{j}=A+B\left(x_{j}-C\right)+\text { random error }
$$

The "random error" term is added to express the fact that the points do not fall exactly on the straight line. This equation applied to air tower 17. More generally, the same process can be applied to any air tower. For the ith air tower, the equation will be

$$
y_{i j}=A_{i}+B_{i}\left(x_{j}-C\right)+\text { random error }
$$

The parameters $A_{j}$ and $B_{j}$ may vary from one air tower to another. The following general facts can be derived from the above [2] equation.then

(1) If $A_{i}$ is constant for all towers, and $B_{i}$ is unity for all towers,

$$
y_{i j}=\text { constant }+\left(x_{j}-C\right)+\text { random error }
$$

In that case, there would only be random differences between the data obtained from different towers. then

(2) If $B_{i}$ is unity for all towers, but $A_{i}$ varies from tower to tower,

$$
y_{i j}=A_{i}+\left(x_{j}-C\right)+\text { random error }
$$

In that case, $A_{i}$ represents a systematic shift for tower $i$, but this shift would be the same for all pressures.

(3) Finally, if $B_{\text {i }}$ is not constant and not equal to unity for all towers, then the systematic shift from tower to tower would vary from one pressure to another. Actually, $A_{j}$ and $B_{i}$ will never be rigorously constant even if no systematic variations are present because of the effects of random fluctuations. It is then necessary to ascertain whether the fluctuations observed in $A_{i}$ and $B_{j}$ exceed what may be expected as a result of chance. 


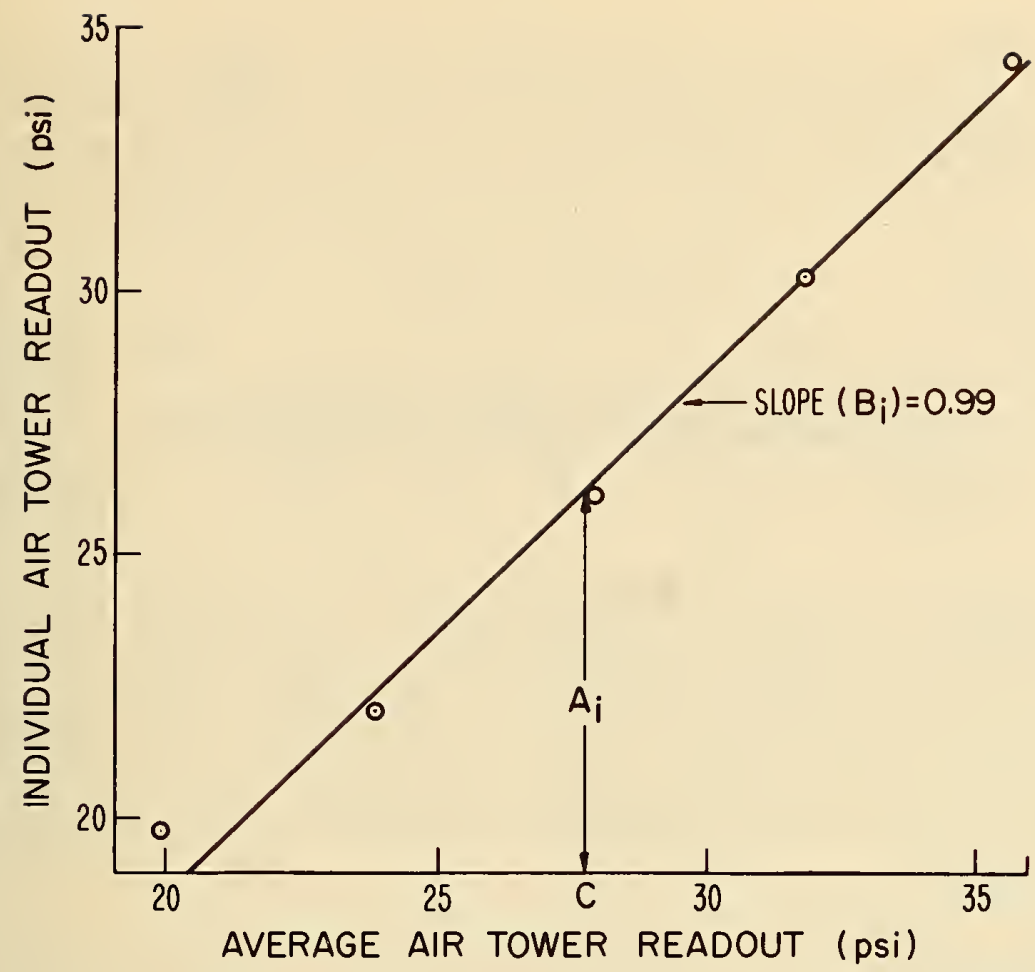

Figure 2. Pressure reading of air tower 17 vs the average reading of 49 air towers.

The values of $A_{j}$ and $B_{j}$ calculated for all 49 towers* are shown in control chart fashion in figure 3 , and the value of $C=27.81$. Also shown on the graphs are two sigma control limits. These limits indicate the variations in $A_{i}$ and $B_{i}$ that would result from random fluctuations alone, and they are such that, in the absence of systematic effects, approximately 95 percent of the plotted points should fall inside the bands determined by these limits. +

*Tower 22 was omitted because of incomplete data.

tA more detailed discussion of this statistical procedure may be found in reference [3]. 

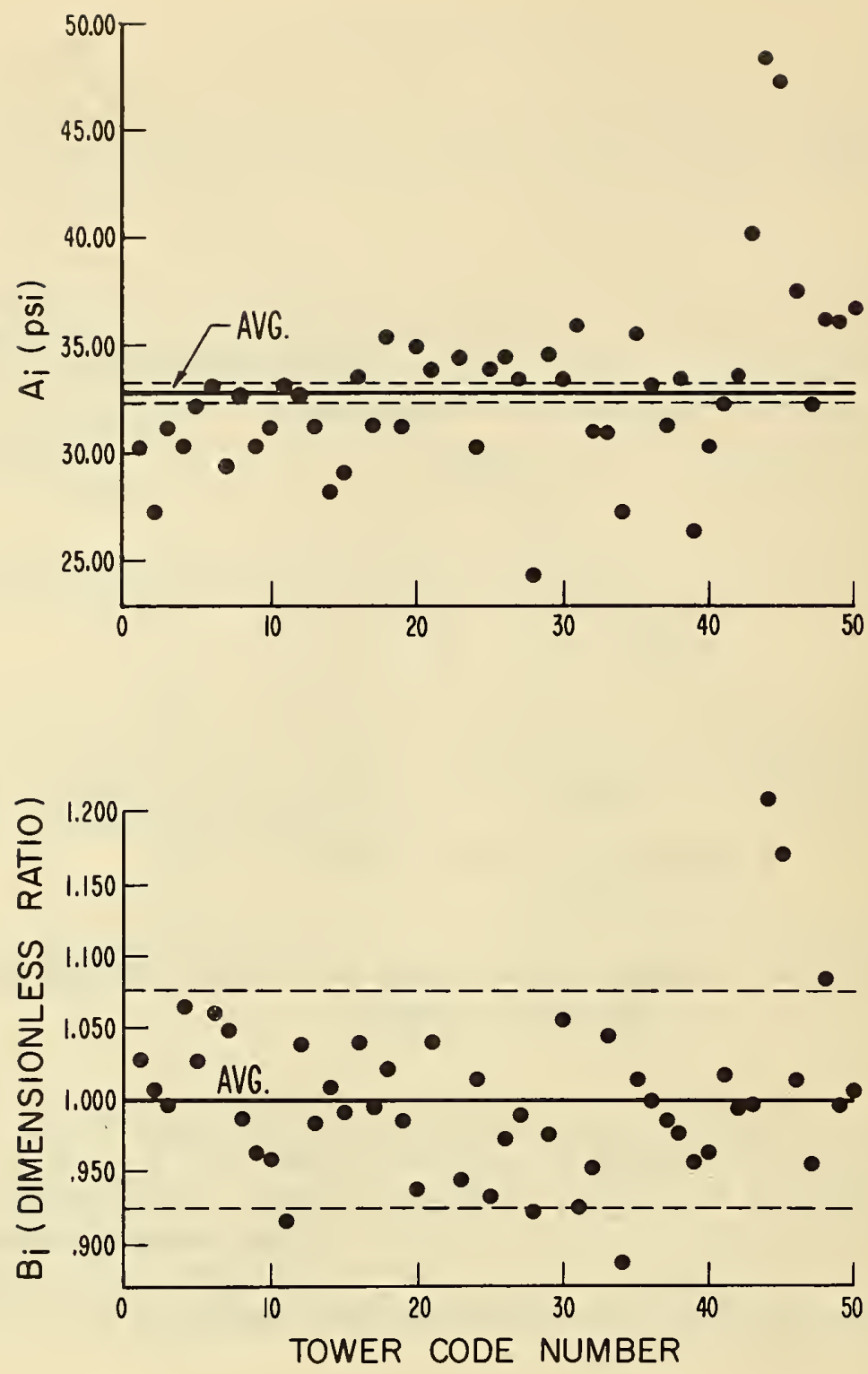

Figure 3. Parameters characterizing systematic differences between air towers.

It is obvious from these graphs that large systematic errors exist in terms of $A_{j}$ between the towers since all but 5 points fell outside the two sigma control limits. All but six of the $B_{i}$ points fall inside the two sigma band indicating that the differences $i_{n}$ the $B_{j}$ are mostly due to random error. Consequently, the systematic shifts observed between towers (fluctuations in $A_{i}$ ) are for all practical purposes constant for all pressures. It follows that calibration of any tower at a single pressure, say 28 psi, would result in a considerable improvement in obtaining uniform readings from different air towers. 
The previous analysis is concerned only with precision, i.e., with agreement between towers. From the viewpoint of accuracy, a comparison must be made between the $x_{j}$, j.e., the average pressures obtained by all 49 towers, and the corresponding nominal values of pressure. The results are shown as follows:

\begin{tabular}{crrrrr} 
Nominal & \multicolumn{5}{c}{} \\
Pressure & 20 & 24 & 28 & 32 & 36 \\
$x_{j}$ & 19.87 & 23.86 & 27.89 & 31.72 & 35.69 \\
Difference & 0.13 & 0.14 & 0.11 & 0.28 & 0.31
\end{tabular}

It is seen that the average pressure for all towers is consistently smaller than the nominal pressure. The differences, however, are relatively small when compared to the random error. The latter is characterized by a standard deviation of $0.54 \mathrm{psi}$. Thus, if systematic errors are eliminated through calibration, a random error will remain which, with 95 percent probability, will fall within approximately \pm 1 psi. The additional inaccuracy measured by the differences shown above is then practically negligible.

In order to obtain a visual appraisal of the large systematic differences between the pressures for the various air towers, frequency diagrams are shown for the deviations from nominal pressure settings in figure 4 for the three settings, 24, 28, and 32 psi, which are the usual pressure 1 imits for passenger car tires. The calculated mean and standard deviations for the three distributions were 0 and 4 psi, respectively. For the purpose of the following discussion, the gage reading differences were approximated to be normally distributed.

Analysis of the data in figure 4 showed the following results:*

(1) A motorist who uses an air tower, which has the characteristics of the sample discussed here, to inflate his tires has only a 20 percent chance of obtaining a pressure within \pm 1 psi of the setting he chooses on the air tower.

(2) The chance that a motorist will inflate his tires to a pressure which differs from the nominal air tower pressure by $\pm x$ psi is given as follows :

\begin{tabular}{cr} 
Pressure Deviation (psi) & Probability \\
\hline \pm 2 psi or more & 62 \\
\pm 3 psi or more & 45 \\
\pm 4 psi or more & 32
\end{tabular}

*The calculations are based on a normal distribution with zero mean and a standard deviation of 4 psi. 

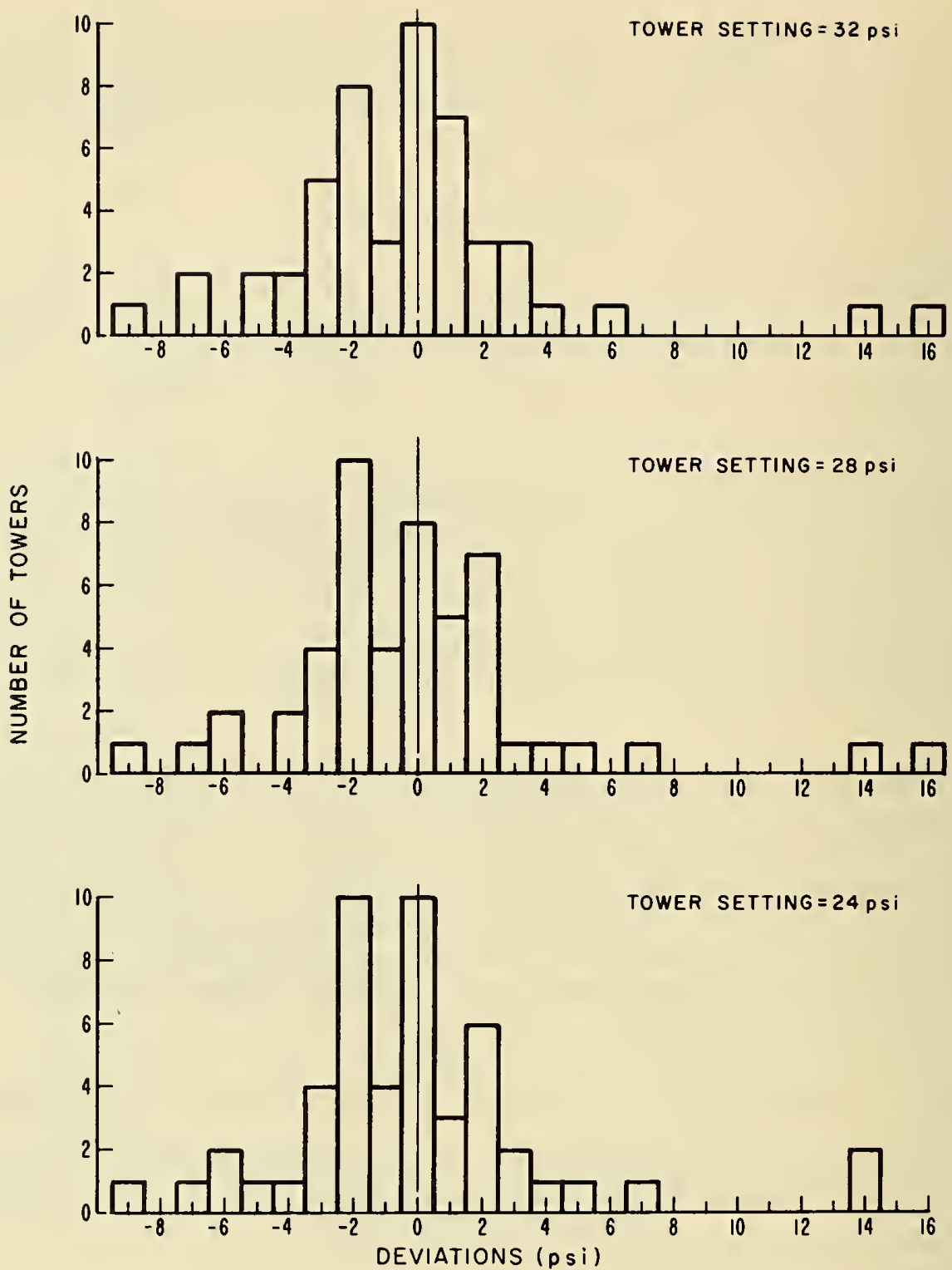

Figure 4. Inflation pressure deviations between air tower and test gage. 


\section{Recommendation}

Results of the survey showed that a motorist, using an air tower in the areas described above, has only a 20 percent chance of inflating his tires within \pm 1 psi of the pressure he chooses on the tower's gage. The test team was informed by a number of service station managers that to the best of their knowledge the air towers were never calibrated. As indicated by the analysis, the air towers which were incorrect at one pressure setting were off on the four other settings by about the same amount. This indicates that a simple periodic calibration at a setting of, for example, 28 psi would be sufficient to reduce the standard deviation of the obtained pressure to $0.5 \mathrm{psi}$.

\section{Acknowledgment}

The statistical analysis was done by Dr. John Mandel, Statistical Consultant, Institute for Materials Research, whose assistance is gratefully acknowledged.

\section{References}

[1] Stevens Institute of Technology Report on Characteristics of Tire Usage in the Eastern United States, A Survey, I.R. Ehrlich and M.P. Jurkat, October 1968.

[2] "Automobile Tire Gauges," Consumers Reports 33, No. 2, 94-96 (1968).

[3] "The Interlaboratory Evaluation of Testing Methods," J. Mandel and T. W. Lashof, ASTM Bu11. 239, July 1959, p. 53-61 (TP133). 



\section{PERIODICALS}

JOURNAL OF RESEARCH reports National Bureau of Standards research and development in physics, mathematics, chemistry, and engineering. Comprehensive scientific papers give complete details of the work, including laboratory data, experimental procedures, and theoretical and mathematical analyses. Illustrated with photographs, drawings, and charts.

Published in three sections, available separately:

\section{Physies and Chemistry}

Papers of interest primarily to scientists working in these fields. This section covers a broad range of physical and chemical research, with major emphasis on standards of physical measurement, fundamental constants, and properties of matter. Issued six times a year. Annual subscription: Domestic, $\$ 9.50$; foreign, $\$ 11.75^{*}$.

\section{Mathematical Sciences}

Studies and compilations designed mainly for the mathematician and theoretical physicist. Topics in mathematical statistics, theory of experiment design, numerical analysis, theoretical physics and chemistry, logical design and programming of computers and computer systems. Short numerical tables. Issued quarterly. Annual subscription: Domestic, $\$ 5.00$; foreign, $\$ 6.25^{*}$.

\section{Engineering and Instrumentation}

Reporting results of interest chiefly to the engineer and the applied scientist. This section includes many of the new developments in instrumentation resulting from the Bureau's work in physical measurement, data processing, and development of test methods. It will also cover some of the work in acoustics, applied mechanics, building research, and cryogenic engineering. Issued quarterly. Annual subscription: Domestic, $\$ 5.00$; foreign, $\$ 6.25^{*}$.

\section{TECHNICAL NEWS BULLETIN}

The best single source of information concerning the Bureau's research, developmental, cooperative and publication activities, this monthly publication is designed for the industry-oriented individual whose daily work involves intimate contact with science and technology-for engineers, chemists, physicists, research managers, product-development managers, and company executives. Annual subscription: Domestic, $\$ 3.00$; foreign, $\$ 4.00^{*}$.
NONPERIODICALS

Applied Mathematics Series. Mathematical tables, manuals, and studies.

Building Science Series. Research results, test methods, and performance criteria of building materials, components, systems, and structures.

Handbooks. Recommended codes of engineering and industrial practice (including safety codes) developed in cooperation with interested industries, professional organizations, and regulatory bodies.

Special Publications. Proceedings of NBŚ conferences, bibliographies, annual reports, wall charts, pamphlets, etc.

Monographs. Major contributions to the technical literature on various subjects related to the Bureau's scientific and technical activities.

National Standard Reference Data Series. NSRDS provides quantitive data on the physical and chemical properties of materials, compiled from the world's literature and critically evaluated.

Product Standards. Provide requirements for sizes, types, quality and methods for testing various industrial products. These standards are developed cooperatively with interested Government and industry groups and provide the basis for common understanding of product characteristics for both buyers and sellers. Their use is voluntary.

Technical Notes. This series consists of communications and reports (covering both other agency and NBS-sponsored work) of limited or transitory interest.

Federal Information Processing Standards Publications. This series is the official publication within the Federal Government for information on standards adopted and promulgated under the Public Law 89-306, and Bureau of the Budget Circular A-86 entitled, Standardization of Data Elements and Codes in Data Systems.

\section{CLEARINGHOUSE}

The Clearinghouse for Federal Scientific and Technical Information, operated by NBS, supplies unclassified information related to Government-generated science and technology in defense, space, atomic energy, and other national programs. For further information on Clearinghouse services, write:

Clearinghouse

U.S. Department of Commerce

Springfield, Virginia 22151

- Difference in price is due to extra cost of foreisn mailing.

Order NBS publications from:

Superintendent of Documents

Government Printing Office

Washington, D.C. 20402 


\section{U.S. DEPARTMENT OF COMMERCE}

WASHINGTON, D.C. 20230

OFFICIAL BUSINESS

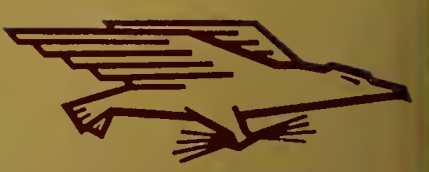

POSTAGE AND FEES PAID U.S. DEPARTMENT OF COMMERO 